\title{
Tendencias de la resistencia a antibióticos en Medellín y en los municipios del área metropolitana entre 2007 y 2012: resultados de seis años de vigilancia
}

\author{
Natalia Andrea Maldonado¹, María Isabel Múnera², Jaime Alberto López³, Patricia Sierra, \\ Carlos Robledo', Jaime Robledo ${ }^{1,5,6}$, Grupo GERMEN* \\ 1 Laboratorio Médico de Referencia S.A.S., Clínica El Rosario, Medellín, Colombia \\ 2 Departamento de Laboratorio, Hospital Pablo Tobón Uribe, Medellín, Colombia \\ 3 Sección de Microbiología, Laboratorio Clínico Hematológico S.A., Medellín, Colombia \\ 4 Control de Infecciones, IPS Universitaria, Medellín, Colombia \\ 5 Unidad de Bacteriología y Micobacterias, Corporación para Investigaciones Biológicas, Medellín, Colombia \\ ${ }^{6}$ Escuela de Ciencias de la Salud, Universidad Pontificia Bolivariana, Medellín, Colombia
}

Introducción. La resistencia bacteriana es un fenómeno mundial, pero su comportamiento varía en el tiempo y el espacio, confiriéndole importancia a los sistemas de vigilancia locales.

Objetivo. Determinar las tendencias de la resistencia a antibióticos entre 2007 y 2012 en instituciones hospitalarias de Medellín y del Área Metropolitana del Valle de Aburrá.

Materiales y métodos. Entre 2007 y 2012 se obtuvieron los porcentajes de resistencia a antibióticos marcadores en 22 instituciones, utilizando el programa Whonet 5.6. Se empleó la guía del Clinical and Laboratory Standards Institute (CLSI) de los años 2009 y 2012 para interpretar los resultados de las pruebas de sensibilidad. Con el programa Epi-Info 6.04 se analizaron tendencias por medio de la prueba de ji al cuadrado de tendencia lineal con un nivel de confianza de $95 \%$; se consideró significativo un valor de $\mathrm{p} \leq 0,05$.

Resultados. Se observó una disminución de la resistencia a oxacilina en Staphylococcus aureus $(p=0,0006)$ y un incremento de la resistencia a vancomicina en Enterococcus faecium $(p=0,0000)$. En Escherichia coli y Serratia marcescens se observó un incremento de la resistencia a ceftazidima, en contraste con una disminución en Klebsiella pneumoniae $(p=0,0000)$ y Enterobacter cloacae $(p=0,058)$. Para K. pneumoniae, S. marcescens y E. cloacae se observó un incremento de la resistencia a carbapenémicos, en contraste con una disminución en Pseudomonas aeruginosa y Acinetobacter baumannii.

Conclusiones. La vigilancia de la resistencia permitió obtener hallazgos importantes como la emergencia de E. faecium resistente a la vancomicina y enterobacterias resistentes a los carbapenémicos. Es indispensable conocer el uso de antibióticos en la región para establecer su influencia en los perfiles encontrados, además de garantizar la calidad de la información emanada de los laboratorios de microbiología.

Palabras clave: resistencia a medicamentos, vigilancia epidemiológica, Staphylococcus aureus resistente a meticilina, resistencia a la vancomicina, Pseudomonas aeruginosa, Enterobacteriaceae.

http://dx.doi.org/10.7705/biomedica.v34i3.1658

Trends in antibiotic resistance in Medellín and municipalities of the Metropolitan Area between 2007 and 2012: Results of six years of surveillance

Introduction: Bacterial resistance is a global phenomenon, but it presents geographic and temporal variations; this is the importance of local surveillance programs.

Objective: To determine trends in antibiotic resistance in hospitals between 2007 and 2012 in Medellín and its Metropolitan Area.

Materials and methods: Percentages of antibiotic resistance between 2007 and 2012 in 22 institutions were obtained using WHONET 5.6 program. For interpretation of susceptibility results, CLSI standards of 2009 and 2012 were used. Using the Epi-Info 6.04 program a trends analysis of antibiotic resistance

\section{Contribución de los autores:}

Natalia Maldonado: diseño del proyecto, recolección de la información de microorganismos aislados y sensibilidad a antibióticos, análisis estadísticos y redacción del manuscrito

Carlos Robledo y Jaime Robledo: diseño del proyecto, coordinación del estudio, supervisión de la recolección de información y el análisis estadístico, participación en la revisión y corrección del manuscrito

María Isabel Múnera, Jaime Alberto López y Patricia Sierra: redacción y corrección del manuscrito 
was done using the chi-square for linear trend with a confidence level of $95 \%$, a value of $p \leq 0.05$ was considered significant.

Results: In six years of surveillance of antibiotic resistance we found a decrease of oxacillin resistance in Staphylococcus aureus $(\mathrm{p}=0.0006)$ and an increase of vancomycin resistance in Enterococcus faecium $(\mathrm{p}=0.0000)$. In Escherichia coli and Serratia marcescens an increase of resistance to ceftazidime was found, in contrast to a decrease in Klebsiella pneumoniae $(p=0.0000)$ and Enterobacter cloacae $(p=0.058)$. K. pneumoniae, $S$. marcescens and E. cloacae showed an increase of carbapenem resistance in contrast to a reduction of carbapenem resistance in Pseudomonas aeruginosa and Acinetobacter baumannii.

Conclusions: The resistance surveillance identified important findings as the emergence of $E$. faecium resistant to vancomycin and carbapenem-resistant Enterobacteriaceae. It is essential to determine the antibiotic use in the region to establish their influence on the resistance profiles, as well as ensuring the quality of information and microbiological procedures in the microbiology laboratories.

Key words: Drug resistance, epidemiological surveillance, methicillin-resistant Staphylococcus aureus, vancomycin resistance, Pseudomonas aeruginosa, Enterobacteriaceae.

http://dx.doi.org/10.7705/biomedica.v34i3.1658

En el mundo se ha observado un incremento en la aparición y diseminación de bacterias resistentes a los antibióticos, situación agravada por el uso indiscriminado que se les da y el bajo número de nuevas alternativas terapéuticas que actualmente están en desarrollo. Como respuesta a este problema, diferentes organizaciones internacionales han promovido el desarrollo y fortalecimiento de los programas de vigilancia orientados a detectar patógenos emergentes, brotes hospitalarios, cambios en los patrones de resistencia y, especialmente, a caracterizar la situación como línea de base para la implementación de estrategias de prevención y control de infecciones, así como de apoyo al diseño de políticas para el manejo prudente de los antibióticos $(1,2)$.

Sin embargo, las infecciones por bacterias resistentes a los antibióticos siguen siendo un problema crítico a pesar de los esfuerzos por implementar estrategias como la higiene de las manos, el uso de precauciones de contacto, las actividades de educación del personal de salud, la gestión de antibióticos, los programas de tamización y la agrupación en cohortes de pacientes colonizados o infectados por gérmenes multirresistentes, entre otras (1-3).

Aunque la resistencia a los antibióticos es un fenómeno mundial, su magnitud y comportamiento varían geográfica y temporalmente. Esta situación le confiere importancia a los sistemas locales y

\section{Correspondencia:}

Jaime Robledo, Laboratorio Médico de Referencia S.A.S. Clínica El Rosario, Calle $63 \mathrm{~N}^{\circ}$ 41-27, piso 2, edificio CIMA, Medellín, Colombia

Teléfono: (574) 295 9000, extensión 9815; fax: (574) 2920793

jrobledo@labmedico.com

Recibido: 17/05/13; aceptado: 09/05/14 nacionales de vigilancia. La implementación de estos sistemas hace posible, además, evaluar y mejorar la calidad de la información con la cual se hace la vigilancia, y mejorar los procedimientos de microbiología por medio de los cuales se obtiene dicha información y que permiten establecer la línea de base para evaluar el impacto de las medidas de prevención y control de la resistencia a los antibióticos (3).

En Colombia varias redes y grupos de investigación han venido desarrollando actividades de vigilancia de resistencia a los antibióticos, entre ellos, el Grupo para el Control de la Resistencia Bacteriana en Bogotá (GREBO), el Centro Internacional de Entrenamiento e Investigaciones Médicas (CIDEIM), la Red de Vigilancia de Eventos Nosocomiales (sic.) del Valle (RENOVA) y el Grupo para el Estudio de la Resistencia a Antibióticos de Medellín (GERMEN). A partir de la información de los laboratorios de microbiología de clínicas y hospitales públicos y privados de las principales ciudades del país, estos grupos generan reportes periódicos y publicaciones nacionales e internacionales sobre los fenotipos y genotipos de resistencia más frecuentes, así como sobre la posible relación clonal en el caso de los estudios de brotes (4).

En el 2010 el actual Ministerio de Salud y Protección Social inició el proceso de construcción de la Red Nacional para la Prevención, Vigilancia y Control de Infecciones Asociadas a la Atención en Salud y Resistencia a los antimicrobianos, a cargo del Instituto Nacional de Salud (5). Con el fin de establecer una línea de base, se recolectó y analizó la información obtenida por las redes de vigilancia entre el 2007 y el 2009, en 79 instituciones de 14 ciudades del país (6). 
El análisis de estos datos y lo reportado por otros estudios locales demostraron que la resistencia a los antibióticos ha aumentado en los últimos años en Colombia, especialmente por la emergencia y diseminación de enterobacterias y otros bacilos Gram negativos con resistencia a antibióticos carbapenémicos (7-10). Sin embargo, en las instituciones hospitalarias de Medellín y en los municipios del área metropolitana se desconocen las variaciones en el tiempo de la resistencia a antibióticos de otros microorganismos trazadores, y no se sabe si la resistencia a carbapenémicos ha mostrado una tendencia al aumento en bacilos Gram negativos y si este comportamiento es similar a lo reportado en otras regiones del país.

Por tal razón se llevó a cabo este estudio descriptivo de tendencias de la resistencia en aislamientos provenientes de pacientes hospitalizados en instituciones de salud, públicas y privadas, de mediano y alto nivel de complejidad, de la ciudad y de los municipios del área metropolitana, en un período consecutivo de seis años.

\section{Materiales y métodos}

Se llevó a cabo un estudio descriptivo y retrospectivo con la información de los resultados de identificación y de las pruebas de sensibilidad a antibióticos de los microorganismos aislados durante el periodo de 2007 a 2012, en 22 instituciones hospitalarias de mediana y alta complejidad de Medellín y los municipios del área metropolitana (Antioquia, Colombia).

Las instituciones participantes fueron el Hospital Pablo Tobón Uribe, la Clínica Cardio VID, la Clínica CES, la Clínica del Prado, la Clínica El Rosario, sede Centro, la Clínica El Rosario, sede Tesoro, la Clínica Las Américas, la Clínica Las Vegas, la Clínica Medellín, la Clínica SOMA, la Clínica Saludcoop Medellín, la Clínica Universitaria Bolivariana, la Fundación Instituto Neurológico de Colombia, la IPS Universitaria - Clínica León XIII, el Hospital General de Medellín - Luz Castro de Gutiérrez, E.S.E., la Clínica Sagrado Corazón, la Clínica Saludcoop Juan Luis Londoño de la Cuesta, y la E.S.E. Hospital La María en Medellín; en Itagüí, la Clínica Antioquia; en Envigado, la E.S.E. Hospital Manuel Uribe Ángel; en Rionegro, la Clínica SOMER y en Bello, la Fundación Clínica del Norte.

De estas 22 instituciones que aportaron información sobre la sensibilidad a antibióticos, $13(59,1 \%)$ lo hicieron sobre seis años, una (4,5\%) sobre cinco años $(4,5 \%)$, una $(4,5 \%)$ sobre cuatro años, tres
$(13,6 \%)$ sobre tres años, y cuatro (18,2\%) sobre uno o dos años.

\section{Pruebas de identificación y sensibilidad a antibióticos}

La información sobre identificación de microorganismos y sobre las pruebas de sensibilidad a antibióticos, se obtuvo de los laboratorios de microbiología con base en los procedimientos de rutina en cada uno de ellos. De las 22 instituciones, 17 (77,3\%) practicaban las pruebas de sensibilidad por el método de microdilución en caldo, empleando sistemas automatizados durante los años en los que suministraron información. De las 13 instituciones que aportaron información sobre los seis años, tres utilizaban el método de difusión de disco en el 2007 y, dos de ellas, en el 2007 y el 2008. En el 2012 todos los laboratorios emplearon sistemas automatizados, siendo el sistema Vitek $2^{\circledR}$ (bioMérieux) el más utilizado en $81,8 \%$ de los laboratorios, seguido de MicroScan Walk Away ${ }^{\circledR}$ (Dade Behring) en el $13,6 \%$ y el Phoenix ${ }^{\circledR}$ (Becton Dickinson) en el 4,5\% de los laboratorios. La información sobre identificación y sensibilidad a antibióticos se extraía de los equipos y se convertía utilizando el programa BacLink 2.0 (Organización Mundial de la Salud).

\section{Auditoría de las bases de datos}

A las bases de datos que contenían la información consolidada de cada institución, se les aplicó un protocolo de normalización previamente establecido que contempló la revisión de los campos de datos completos de cada registro y la normalización de los tipos de localización, de acuerdo con las siguientes categorías: unidades de cuidados intensivos, unidades de cuidados intermedios y otros servicios de hospitalización, pacientes ambulatorios y urgencias. Además, se verificaron los resultados infrecuentes de sensibilidad a antibióticos en la región, de acuerdo con la recomendación para el análisis y la presentación de resultados acumulativos de pruebas de sensibilidad de la guía del Clinical and Laboratory Standards Institute (CLSI) M39-A4 del 2014 (11).

\section{Garantía de calidad en el laboratorio de microbiología}

Todos los laboratorios de microbiología participantes tenían un programa de control de calidad interno periódico para las pruebas de sensibilidad a antibióticos empleando cepas ATCC de referencia, y todos ellos participaban en programas nacionales de control de calidad externos; algunos, además, 
participaban en programas de control de calidad internacionales. Entre el 2008 y el 2011, el Grupo GERMEN implementó un programa de control de calidad entre laboratorios orientado a determinar su capacidad para detectar nuevos patrones de resistencia, en el cual se evaluaban la identificación del microorganismo, los resultados de las pruebas de sensibilidad a antibióticos y de las de tamización y confirmación de la sensibilidad, así como su capacidad de inferir los mecanismos de resistencia con base en estos resultados.

\section{Criterios de interpretación y análisis estadístico}

Utilizando el programa Whonet 5.6, se hicieron análisis descriptivos de frecuencias y porcentajes de resistencia a los antibióticos marcadores en patógenos considerados de gran impacto clínico en el entorno hospitalario, como son Staphylococcus aureus resistente a la meticilina (SAMR), Enterococcus spp. resistente a la vancomicina, Acinetobacter baumannii y Pseudomonas aeruginosa resistentes a los carbapenémicos, y especies de la familia Enterobacteriaceae, como Escherichia coli, Klebsiella pneumoniae, Serratia marcescens y Enterobacter cloacae resistentes a las cefalosporinas de tercera generación y a los carbapenémicos (12). Se analizaron los aislamientos provenientes de pacientes hospitalizados, con excepción de aquellos obtenidos en servicios de urgencias y de consulta externa, considerando solo el primer aislamiento de cada paciente.

En el análisis de tendencias de la resistencia a antibióticos, se excluyeron los aislamientos provenientes de cultivos de vigilancia epidemiológica y se emplearon los criterios establecidos por el CLSI en la guía M100-S19 de 2009 (13). Se consideraron como resistentes los aislamientos de $S$. aureus con una concentración inhibitoria mínima (CIM) para oxacilina $\geq 4 \mu \mathrm{g} / \mathrm{ml}$ y los de Enterococcus spp. con una CIM para vancomicina $\geq 32 \mu \mathrm{g} / \mathrm{ml}$. En cuanto a la familia Enterobacteriaceae, se consideraron resistentes los aislamientos con $\mathrm{CIM} \geq 32 \mu \mathrm{g} / \mathrm{ml}$ para ceftazidima, $\geq 64 \mu \mathrm{g} / \mathrm{ml}$ para ceftriaxona y $\geq 4 \mu \mathrm{g} / \mathrm{ml}$ para ciprofloxacina, así como CIM $\geq 8 \mu \mathrm{g} / \mathrm{ml}$ para ertapenem y $\geq 16 \mu \mathrm{g} / \mathrm{ml}$ para imipenem y meropenem; en $P$. aeruginosa y $A$. baumannii se consideraron resistentes los aislamientos con $\mathrm{CIM} \geq 16 \mu \mathrm{g} / \mathrm{ml}$ para los dos carbapenémicos analizados.

Además, se analizaron las tendencias de la resistencia a ceftazidima y a carbapenémicos empleando los nuevos criterios de interpretación propuestos en la guía del CLSI M100-S23 de 2013 (14). Con estos criterios se interpretó la información de los años 2010 a 2012 para enterobacterias, mientras que para $P$. aeruginosa, solo la correspondiente al 2012.

El análisis estadístico de los datos se hizo empleando la herramienta Epitable del programa Epi-Info 6.04. Se analizaron las tendencias mediante la prueba de ji al cuadrado de tendencia lineal, con un nivel de confianza de $95 \%$; se consideró estadísticamente significativo un valor de $p \leq 0,05$.

\section{Resultados}

\section{Frecuencia de los microorganismos}

Se analizaron 106.408 aislamientos provenientes de pacientes hospitalizados durante los seis años. El número de aislamientos analizados por año varió de 12.181 en el 2007 a 21. 746 en el 2012. Esta información, así como el total de instituciones que aportaron información por año y la distribución por percentiles del número de aislamientos, se presenta en el cuadro 1.

Con respecto a la distribución según servicios hospitalarios, 27.955 (26,3\%) provenían de las unidades de cuidados intensivos y $78.453(73,7 \%)$ de salas generales. La muestra clínica más

Cuadro 1. Número de aislamientos por año, número de instituciones que aportaron aislamientos cada año y distribución por percentiles del número de aislamientos aportados por las instituciones

\begin{tabular}{lrrrrrr}
\hline & $\mathbf{2 0 0 7}$ & $\mathbf{2 0 0 8}$ & $\mathbf{2 0 0 9}$ & $\mathbf{2 0 1 0}$ & $\mathbf{2 0 1 1}$ & $\mathbf{2 0 1 2}$ \\
\hline Total de aislamientos analizados por año & 12.181 & 14.430 & 16.549 & 19.818 & 21.684 & 21.746 \\
Total de instituciones que aportaron información por año & 13 & 14 & 15 & 18 & 19 & 22 \\
Distribución del número de aislamientos aportados por las & & & & & & \\
instituciones por año & & & & & \\
Mín. & 313 & 262 & 281 & 287 & 150 & 102 \\
P25 & 642 & 664 & 693 & 538 & 587 & 561 \\
P50 & 843 & 761 & 837 & 760 & 786 & 705 \\
P75 & 1.167 & 1.304 & 1.491 & 1.429 & 1.476 & 1.137 \\
Máx. & 1.986 & 2.850 & 2.957 & 2.493 & 2.592 & 3.307 \\
\hline
\end{tabular}

Mín.: valor mínimo; P25: percentil 25; P50: percentil 50; P75: percentil 75; Máx.: valor máximo 
frecuente fue la de orina, que aportó el 33,3\% de los aislamientos, seguida de sangre en hemocultivos $(17,02 \%)$, secreciones (sin especificar el sitio anatómico) (13,3\%), muestras del aparato respiratorio $(9,69 \%)$ y muestras obtenidas del abdomen (5,41\%), incluido el líquido peritoneal, la bilis y los abscesos abdominales.

Escherichia coli fue el microorganismo más frecuentemente aislado, tanto en salas generales de hospitalización $(29,8 \%)$ como en unidades de cuidados intensivos (15,3\%). En los servicios de otras áreas hospitalarias, el segundo más frecuente fue $S$. aureus (12,8\%), seguido de K. pneumoniae $(9,0 \%)$ y $P$. aeruginosa $(5,7 \%)$, mientras que en las unidades de cuidados intensivos de Medellín y otros municipios del área metropolitana, los microorganismos más frecuentes después de $E$. coli fueron de $K$. pneumoniae $(14,1 \%$ y $P$. aeruginosa $(9,1 \%)$. Los aislamientos de las diferentes especies del género Candida provenientes de las unidades de cuidados intensivos, duplicaron la proporción de aquellos obtenidos en otros servicios de hospitalización (figura 1).

En el análisis por tipo de muestra se observó que la especie predominante en muestras de orina fue E. coli, con el 52,9\% del total de aislamientos. En los hemocultivos, las especies del género
Staphylococcus spp. representaron el $41,4 \%$ de los aislamientos, $12,7 \%$ de estos correspondieron a $S$. aureus, mientras que $28,7 \%$ fueron Staphylococcus negativos para coagulasa. En muestras de origen respiratorio, $K$. pneumoniae y $P$. aeruginosa fueron las especies más frecuentes, con 19,0 y el $14,7 \%$ de los aislamientos, respectivamente (cuadro 2).

\section{Tendencias de la resistencia a antibióticos}

Los porcentajes anuales de resistencia a cada antibiótico marcador en el periodo comprendido entre 2007 y 2012 y los resultados del análisis de tendencias de la resistencia, están consignados en el cuadro 3.

Como puede observarse, en las instituciones hospitalarias de Medellín y de los municipios cercanos se encontró una disminución significativa de la resistencia de $S$. aureus a oxacilina, que pasó de $33,8 \%$ en el 2007 a $29,4 \%$ en el $2012(m=-$ $0,01 ; p=0,0006)$. En cuanto a Enterococcus spp., el comportamiento de la resistencia a la vancomicina observado varió según la especie; mientras que la resistencia de E. faecalis permaneció estable en los seis años analizados, en $E$. faecium se observó una tendencia significativa al incremento de la resistencia, que pasó de $0,0 \%$ en el 2007

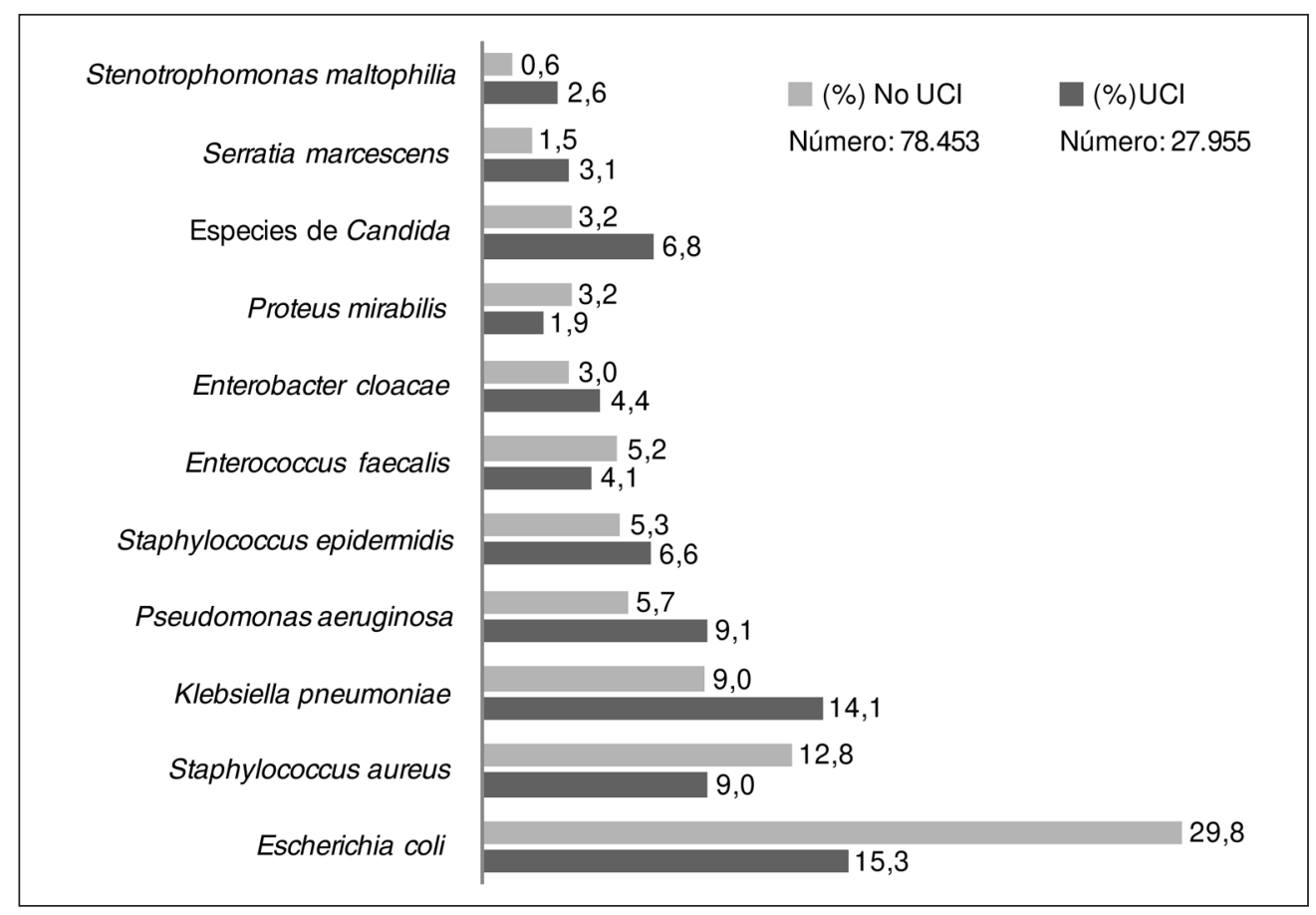

Figura 1. Microorganismos más frecuentemente aislados de pacientes hospitalizados en las unidades de cuidados intensivos (UCI) y en otras salas (No UCl) entre 2007 y 2012 en instituciones de Medellín y municipios cercanos 
Cuadro 2. Distribución y orden de frecuencia de las especies aisladas en muestras de pacientes en instituciones hospitalarias de Medellín y otros municipios del área metropolitana entre enero de 2007 y diciembre de 2012

\begin{tabular}{|c|c|c|c|c|c|c|c|c|}
\hline \multirow{2}{*}{ Microorganismo } & \multicolumn{2}{|c|}{ Todas las muestras } & \multicolumn{2}{|l|}{ Sangre } & \multicolumn{2}{|l|}{ Orina } & \multicolumn{2}{|c|}{ Muestras respiratorias } \\
\hline & $\begin{array}{l}\text { No. }(\%) \text { de } \\
\text { aislamientos }\end{array}$ & Orden & $\begin{array}{c}\text { No. (\%) de } \\
\text { aislamientos }\end{array}$ & Orden & $\begin{array}{l}\text { No. (\%) de } \\
\text { aislamientos }\end{array}$ & Orden & $\begin{array}{c}\text { No. }(\%) \text { de } \\
\text { aislamientos }\end{array}$ & Orden \\
\hline Escherichia coli & $27.623(26,0)$ & 1 & $2.352(13,0)$ & 2 & $18.768(52,9)$ & 1 & $715 \quad(6,9)$ & 4 \\
\hline Staphylococcus aureus & $12.571(11,8)$ & 2 & $2.298(12,7)$ & 3 & $354(1,0)$ & & $1.478(14,3)$ & 3 \\
\hline $\begin{array}{l}\text { Staphylococcus negativa } \\
\text { para coagulasa }\end{array}$ & $11.227(10,6)$ & 3 & $5.196(28,7)$ & 1 & $667(1,8)$ & 8 & $418(4,1)$ & 9 \\
\hline Klebsiella pneumoniae & $10.989(10,3)$ & 4 & $1.802(9,9)$ & 4 & $3.986(11,2)$ & 3 & $1.959(19,0)$ & 1 \\
\hline Pseudomonas aeruginosa & $6.977(6,6)$ & 5 & $921 \quad(5,1)$ & 5 & $1.697(4,7)$ & 4 & $1.518(14,7)$ & 2 \\
\hline Enterococcus spp. & & 6 & & 6 & & 2 & & \\
\hline Enterococcus faecalis & $5.195(4,9)$ & & $521 \quad(2,9)$ & & $2.101 \quad(5,9)$ & & & \\
\hline Enterococcus faecium & $701 \quad(0,7)$ & & $93(0,5)$ & & $148 \quad(0,4)$ & & & \\
\hline Enterobacterspp. & & 7 & & 8 & & 7 & & 5 \\
\hline Enterobacter cloacae & $3.598 \quad(3,4)$ & & $491 \quad(2,7)$ & & $831 \quad(2,3)$ & & $510 \quad(4,9)$ & \\
\hline Candida spp. & & 8 & & 7 & & 6 & & 8 \\
\hline Candida no albicans & $4.063(3,8)$ & & $369(2,0)$ & & $1.640(4,6)$ & & $149(1,4)$ & \\
\hline Candida albicans & $2.360 \quad(2,2)$ & & $298(1,6)$ & & $813(2,2)$ & & $298 \quad(2,9)$ & \\
\hline Proteus mirabilis & $3.076 \quad(2,9)$ & 9 & $151(0,8)$ & & $1.677 \quad(4,7)$ & 5 & & \\
\hline Serratia marcescens & $2.012(1,9)$ & 10 & $536 \quad(3,0)$ & 9 & & & $439 \quad(4,3)$ & 7 \\
\hline Klebsiella oxytoca & $1.409(1,3)$ & 11 & & & $363(1,0)$ & 10 & $197(1,9)$ & \\
\hline Morganella morganii & $1.296(1,2)$ & 12 & & & $373(1,0)$ & 9 & & \\
\hline Stenotrophomonas maltophilia & $1.173(1,1)$ & 13 & $182(1,0)$ & & & & $503 \quad(4,9)$ & 6 \\
\hline Acinetobacter baumannii & $1.152(1,1)$ & 14 & $280(1,5)$ & 10 & & & $253(2,5)$ & 10 \\
\hline Citrobacter freundii & $1.026(1,0)$ & 15 & & & & & & \\
\hline Otros & $9.960 \quad(9,4)$ & & $1.658(9,1)$ & & $903 \quad(2,5)$ & & $1.706(16,5)$ & \\
\hline Total & 106.408 & & 18.112 & & 35.458 & & 10.316 & \\
\hline
\end{tabular}

a $16,3 \%$ en el 2012 , mostrando altos porcentajes de resistencia en el periodo comprendido entre 2009 y 2011 ( $m=0,02 ; p=0,000)$. Las tendencias de la resistencia en cocos Gram positivos pueden observarse en la figura 2.

En E. coli se observó una disminución significativa de la resistencia a las fluoroquinolonas (ciprofloxacina), que pasó de $39,4 \%$ en 2007 a $31,9 \%$ en 2012 ( $m=-0,01 ; p=0,000)$. Asimismo, se observaron cambios importantes en la resistencia a cefalosporinas de tercera generación durante el periodo de estudio. En E. coli y S. marcescens se observó un incremento significativo de la resistencia a la ceftazidima; en contraste, la resistencia a las cefalosporinas mostró una tendencia a la disminución en $K$. pneumoniae $(m=-0,01 ; p=0,000)$ y E. cloacae $(m=-0,01 ; p=0,058)$ (figura 3 ).

La resistencia a los tres antibióticos carbapenémicos analizados para $E$. coli, permaneció constante en estos seis años y para el 2012 fue de $0,4 \%$ para ertapenem, de $0,2 \%$ para imipenem y de $0,1 \%$ para meropenem. En K. pneumoniae y $S$. marcescens se observó un incremento de la resistencia a imipenem y meropenem, así como un incremento de la resistencia a ertapenem en E. cloacae (figura 4). En contraste, se observó una tendencia significativa a la disminución de la resistencia a imipenem $(m=0,01 ; p=0,000)$ y meropenem $(m=-0,01 ; \mathrm{p}=0,000)$ en $P$. aeruginosa $\mathrm{y}$, para meropenem, en $A$. baumannii (cuadro $3 \mathrm{y}$ figura 5).

\section{Tendencias de la resistencia a los antibióticos según los criterios de interpretación vigentes}

En el cuadro 4 se presentan las tendencias de la resistencia a los antibióticos en enterobacterias y $P$. aeruginosa una vez implementados los criterios de interpretación recomendados por el CLSI en la guía M100-S23 de 2013 (14).

Para E. coli, S. marcescens y K. pneumoniae, la adopción de los criterios de interpretación vigentes para ceftazidima en el periodo 2010-2012, no implicó un cambio en la tendencia al aumento de la resistencia observada en el análisis hecho con los puntos de corte anteriores. En contraste, en E. cloacae se observó una tendencia al aumento de la resistencia a la ceftazidima cuando se aplicaron los nuevos puntos de corte, aunque no fue estadísticamente significativa. 


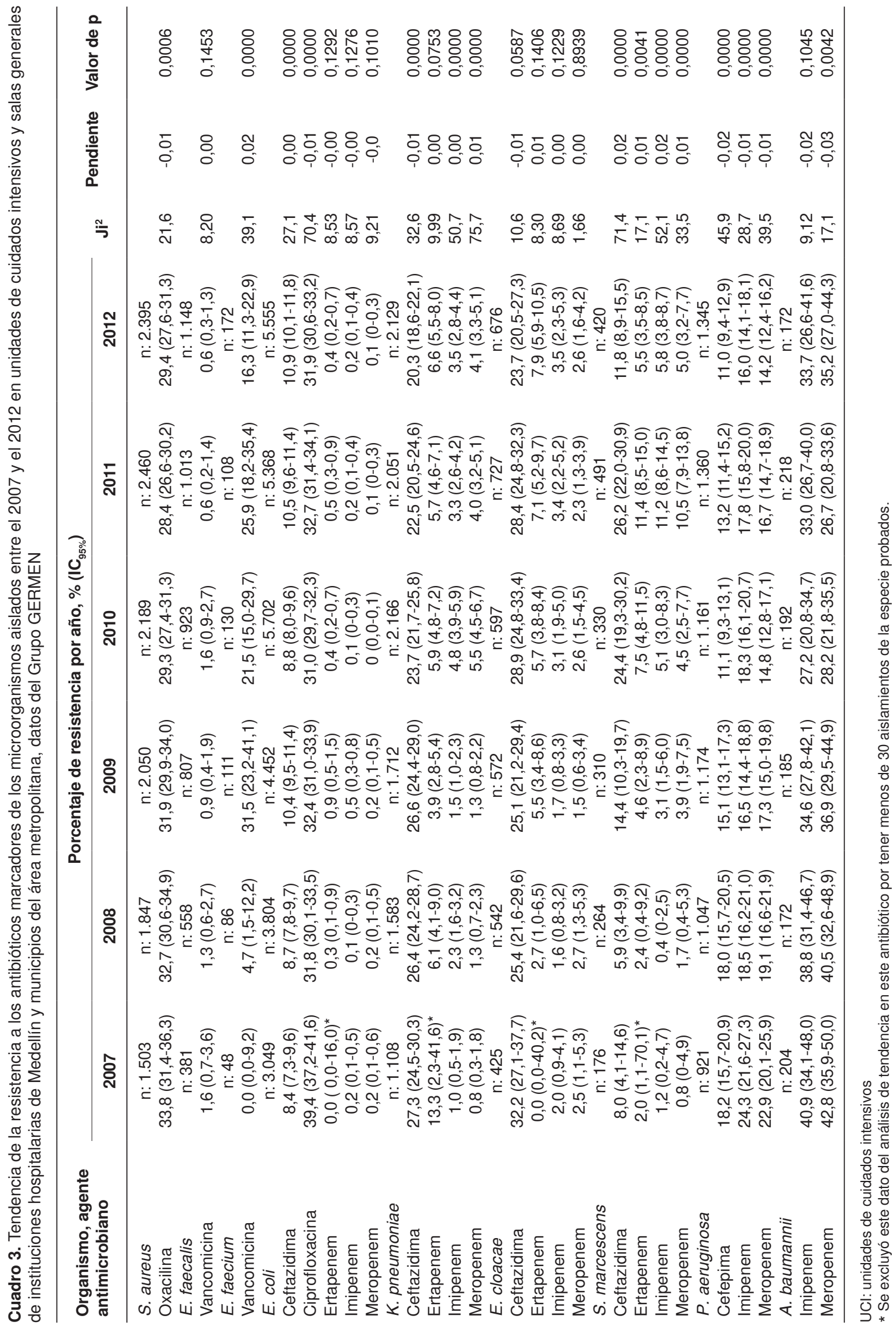




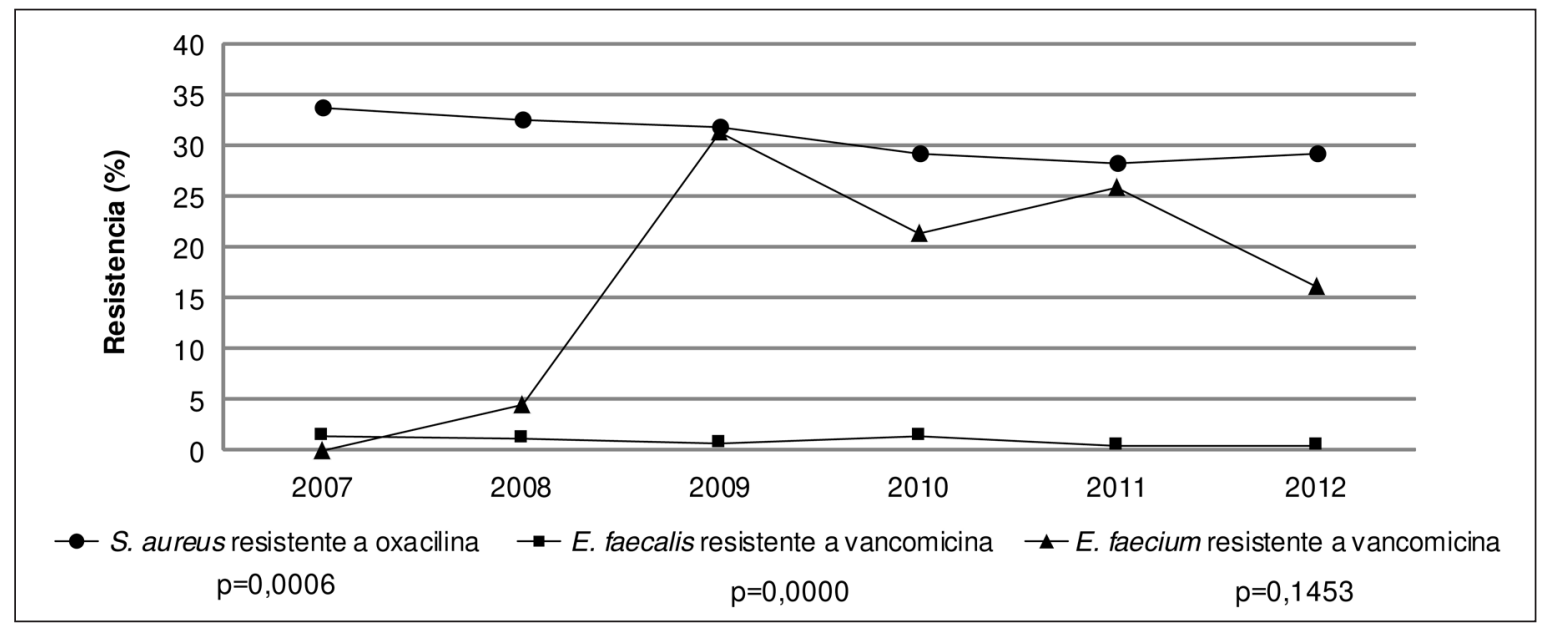

Figura 2. Tendencias de la resistencia a antibióticos en cocos Gram positivos en Medellín y municipios vecinos entre 2007 y 2012 ; datos del grupo GERMEN

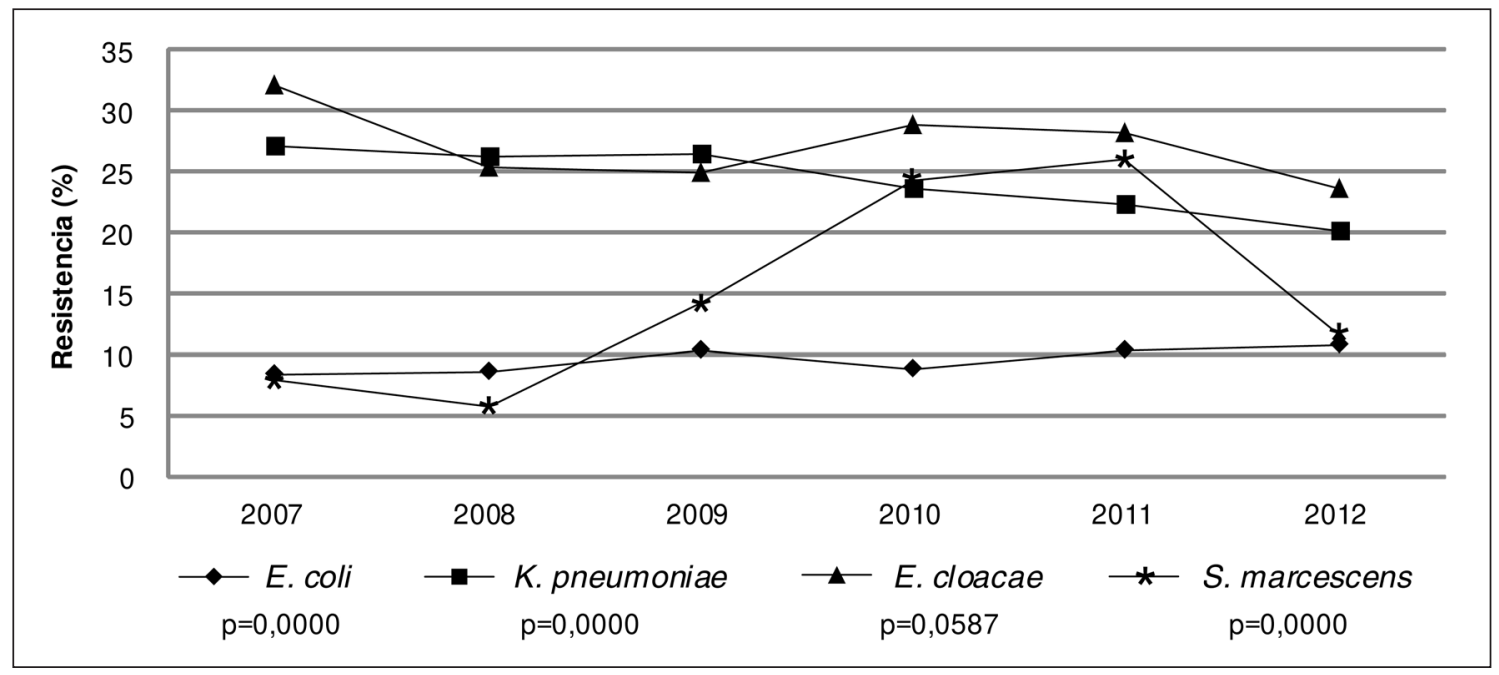

Figura 3. Tendencias de la resistencia a ceftazidima en enterobacterias en Medellín y municipios vecinos entre 2007 y 2012 ; datos del grupo GERMEN

Las tendencias de la resistencia a los carbapenémicos en enterobacterias y $P$. aeruginosa fueron similares al aplicar los puntos de corte recomendados en el 2009 y los recomendados en el 2012 por el CLSI.

\section{Discusión}

Este sistema de vigilancia permitió determinar las tendencias de la resistencia a los antibióticos en Medellín y en otros municipios del área metropolitana en un período de seis años. Particularmente, permitió la identificación de patógenos emergentes como E. faecium resistente a la vancomicina y enterobacterias resistentes a los carbapenémicos. La divulgación periódica de los fenotipos de resistencia de los microorganismos más frecuentes durante el período de vigilancia, también ha servido como insumo en el desarrollo de guías para la aplicación del tratamiento antimicrobiano adecuado, así como para la selección del tratamiento empírico en las instituciones de la región.

Uno de los hallazgos más importantes de este estudio se refiere a la disminución significativa de la proporción de aislamientos de $S$. aureus resistentes a la meticilina (SARM). Este comportamiento también fue reportado por el Grupo para el Control de la Resistencia Bacteriana de Bogotá en 35 


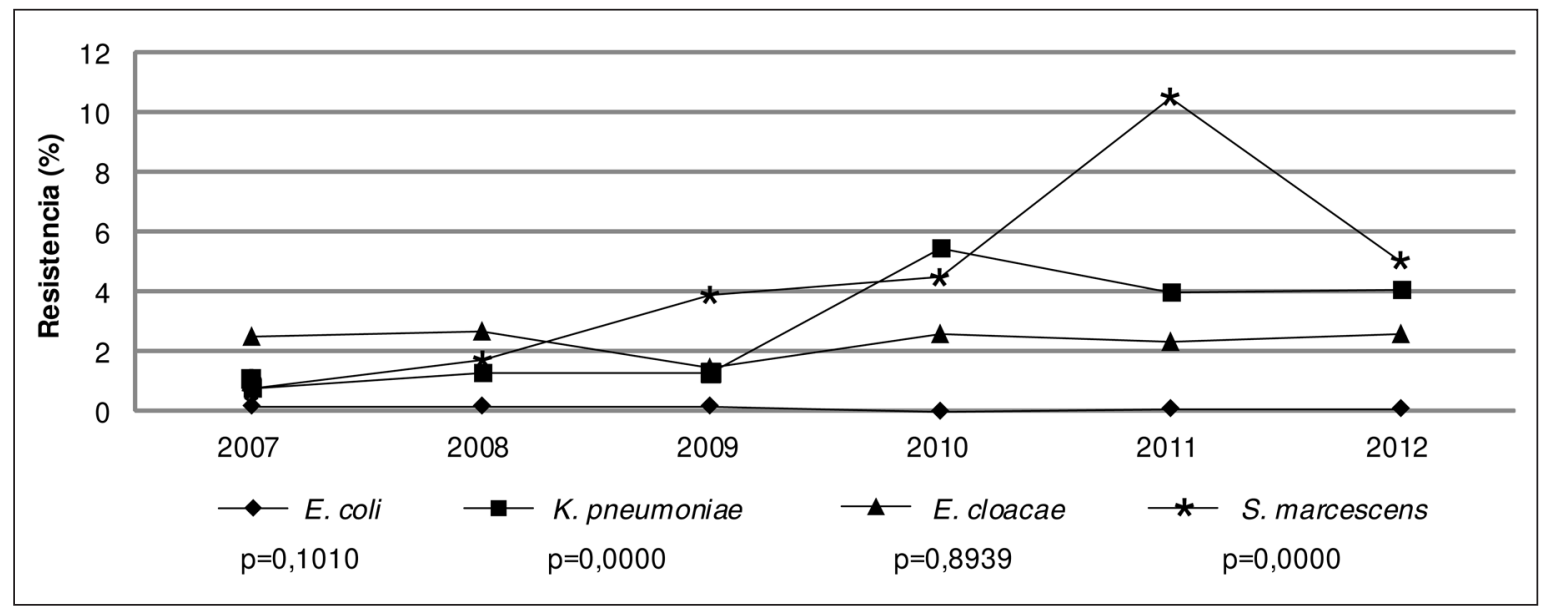

Figura 4. Tendencias de la resistencia a meropenem en enterobacterias en Medellín y municipios vecinos entre 2007 y 2012 ; datos del grupo GERMEN

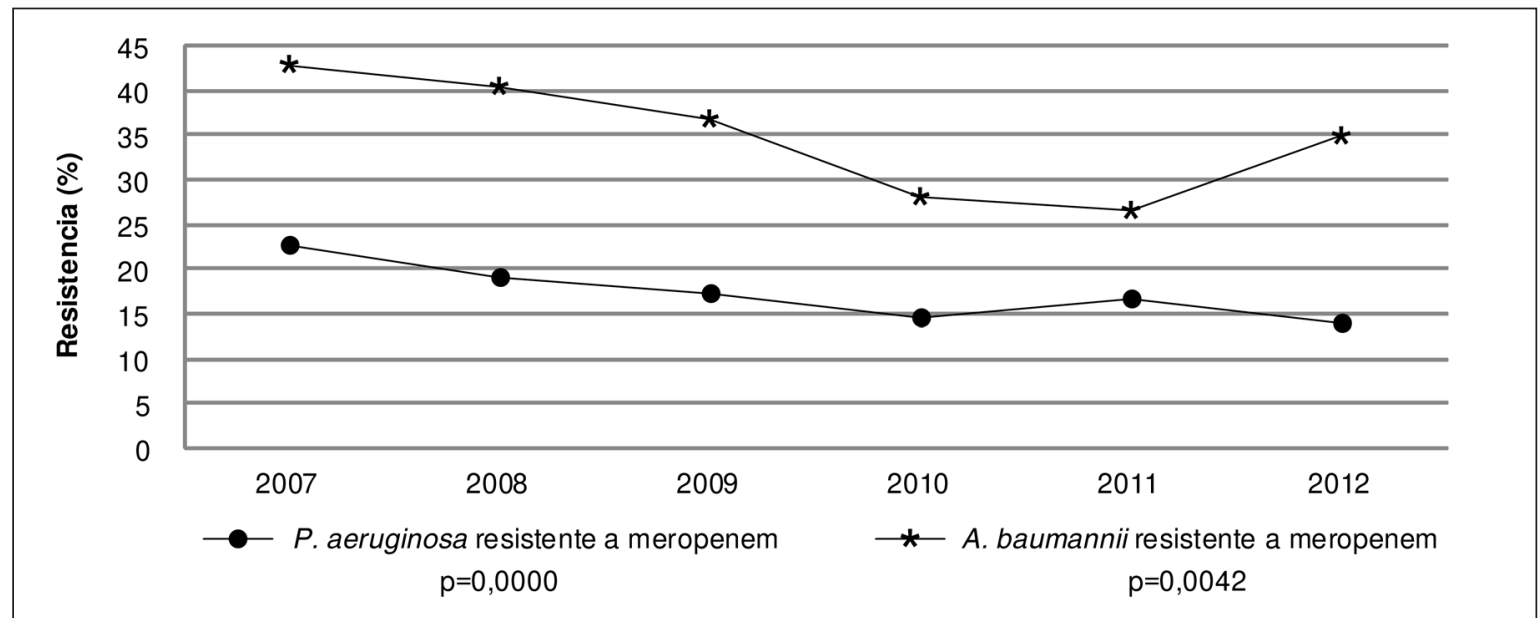

Figura 5. Tendencias de la resistencia a carbapenémicos en Pseudomonas aeruginosa y Acinetobacter baumanni en Medellín y municipios vecinos entre 2007 y 2012; datos del grupo GERMEN

instituciones de Colombia, 29 de ellas de Bogotá, en las que se evidenció una reducción del $27,7 \%$ de la resistencia a la oxacilina entre 2001 y 2009 (15). Asimismo, en un trabajo que consolidó la información de resistencia a antibióticos de los grupos y redes de vigilancia del país, aunque con una ventana menor de observación a la del presente estudio, se demostró una disminución de la resistencia en aislamientos de SARM provenientes de las unidades de cuidados intensivos y de otras áreas de hospitalización, la cual pasó de 40,0\% en 2007 a 28,1 \% en 2009 (6). De la misma manera, el Programa T.E.S.T. reportó un porcentaje de resistencia a la oxacilina de 55,6\% en el 2005 y de $16,9 \%$ en el 2010 , en los hospitales colombianos que participaron (16).
La disminución del porcentaje de resistencia de $S$. aureus a la oxacilina, también se ha evidenciado en otros países. Entre 2007 y 2011, en Canadá, Lagacé-Wiens, et al., encontraron una reducción de la proporción de resistencia de 33,0 a 21,2 \% en pacientes hospitalizados en servicios generales, y de 28,2 a $17,7 \%$ en aquellos hospitalizados en unidades de cuidados intensivos (17). En el Reino Unido, Livermore describió un incremento gradual de SARM entre 1997 y 2000, momento en el cual la frecuencia fue de $40 \%$; sin embargo, desde el 2003 se ha reducido, hasta alcanzar $15 \%$ en el 2011 (18).

Según Stefani, et al., la tendencia a la disminución de los aislamientos de SARM puede tener una explicación en la que intervienen múltiples factores; 
Cuadro 4. Tendencias de la resistencia a antibióticos adoptando puntos de corte vigentes de los microorganismos aislados entre 2007 y 2012 en las unidades de cuidados intensivos y en salas generales de instituciones hospitalarias de Medellín y de los municipios del área metropolitana, datos del Grupo GERMEN

\begin{tabular}{|c|c|c|c|c|c|c|}
\hline \multirow{2}{*}{$\begin{array}{l}\text { Microorganismo, agente } \\
\text { antimicrobiano }\end{array}$} & \multicolumn{3}{|c|}{ Porcentaje de resistencia por año, \% (IC $\left.{ }_{95 \%}\right)$} & \multirow[t]{2}{*}{$\mathbf{J i}^{2}$} & \multirow{2}{*}{ Pendiente } & \multirow{2}{*}{$\begin{array}{l}\text { Valor } \\
\text { de } p\end{array}$} \\
\hline & 2010 & 2011 & 2012 & & & \\
\hline \multicolumn{7}{|l|}{ Escherichia coli } \\
\hline Ceftazidima & $11,8(10,9-12,8)$ & $12,6(11,6-13,7)$ & $13,4(12,5-14,4)$ & 78,4 & 0,01 & 0,0000 \\
\hline Ertapenem & $0,7 \quad(0,4-1,3)$ & $0,8 \quad(0,5-1,4)$ & $0,8 \quad(0,5-1,3)$ & 3,8 & 0,00 & 0,5529 \\
\hline Meropenem & $0,0 \quad(0,0-0,2)$ & $0,2 \quad(0,1-0,4)$ & $0,2 \quad(0,1-0,4)$ & 5,69 & 0,00 & 0,3379 \\
\hline \multicolumn{7}{|l|}{ Klebsiella pneumoniae } \\
\hline Ceftazidima & $24,6(22,5-26,8)$ & $24,0(21,9-26,2)$ & $21,8(20,0-23,7)$ & 17,8 & $-0,01$ & 0,0031 \\
\hline Ertapenem & $9,1 \quad(7,4-11,1)$ & $7,0 \quad(5,6-8,7)$ & $8,1 \quad(6,8-9,7)$ & 24,9 & 0,01 & 0,0001 \\
\hline Meropenem & $6,3 \quad(5,1-7,7)$ & $4,4 \quad(3,5-5,5)$ & $4,9 \quad(4,0-6,0)$ & 92,2 & 0,01 & 0,0000 \\
\hline \multicolumn{7}{|l|}{ Enterobacter cloacae } \\
\hline Ceftazidima & $29,8(25,4-34,6)$ & $31,1(27,2-35,2)$ & $28,8(25,3-32,6)$ & 9,11 & 0,00 & 0,1045 \\
\hline Ertapenem & $13,4 \quad(9,8-17,9)$ & $15,8(12,5-19,7)$ & $18,2(15,0-21,8)$ & 52,3 & 0,04 & 0,0000 \\
\hline Meropenem & $3,1 \quad(1,7-5,5)$ & $5,5 \quad(3,8-7,8)$ & $5,2(3,7-7,3)$ & 16,6 & 0,01 & 0,0052 \\
\hline \multicolumn{7}{|l|}{ Serratia marcescens } \\
\hline Ceftazidima & $26,1(20,6-32,5)$ & $32,3(27,6-37,4)$ & $16,6(13,1-20,7)$ & 90,1 & 0,03 & 0,0000 \\
\hline Ertapenem & $7,6 \quad(4,4-12,7)$ & $14,5(10,9-19,0)$ & $6,7 \quad(4,3-10,1)$ & 24,9 & 0,01 & 0,0001 \\
\hline Meropenem & $6,5 \quad(3,8-10,7)$ & $11,2(8,4-14,8)$ & $5,7 \quad(3,7-8,6)$ & 32,9 & 0,01 & 0,0000 \\
\hline \multicolumn{7}{|l|}{ Pseudomonas aeruginosa } \\
\hline Imipenem & * & * & $21 \quad(18,9-23,3)$ & 25,4 & $-0,00$ & 0,0001 \\
\hline Meropenem & * & * & $18,1(16,1-20,3)$ & 24,3 & $-0,00$ & 0,0001 \\
\hline
\end{tabular}

*Los porcentajes de resistencia de 2007 a 2009 están incluidos en el cuadro 2.

El análisis de tendencias para enterobacterias presentado en este cuadro, se hizo considerando la información del 2007 al 2009 interpretada con puntos de corte del CLSI para el 2009, y la del periodo 2010-2012, con puntos de corte del CLSI para el 2012. Para P. aeruginosa, solo el año 2012 se interpretó con los puntos de corte vigentes.

algunos de ellos son los patrones de uso de los antibióticos, la diseminación clonal, la adaptación de los microorganismos a los diversos entornos, su capacidad patógena y de colonización asociada, el impacto de las estrategias de lavado de manos y la búsqueda activa de individuos colonizados, entre otros (19).

A pesar de la disminución de la resistencia de $S$. aureus a la oxacilina, recientemente se ha encontrado, no solamente en SARM sino en aislamientos de esta especie sensibles a la oxacilina, una reducción de la sensibilidad a la vancomicina, usualmente con una CIM entre 1 y $2 \mu \mathrm{g} / \mathrm{ml}$, fenómeno este denominado "MIC creep" y que se asocia a una menor eficacia del tratamiento con vancomicina en casos de infecciones complicadas, como neumonía y bacteriemia (20). Aunque en nuestra región aún no se han presentado aislamientos resistentes a este antibiótico, de los aislamientos de $S$. aureus recolectados entre 2007 y 2012 y analizados en este estudio, el 42,2 \% mostró una CIM de $1 \mu \mathrm{g} /$ $\mathrm{ml}$ para la vancomicina y, 17,1\%, una CIM de $2 \mu \mathrm{g} /$ $\mathrm{ml}$. Esto hace indispensable mantener la vigilancia de la sensibilidad de $S$. aureus a la vancomicina, y la implementación de métodos de tamización y confirmatorios adicionales a los procedimientos de rutina para pruebas de sensibilidad.
La emergencia de E. faecium con resistencia a la vancomicina se evidenció en el análisis de tendencias de este estudio. Este es un fenómeno descrito en otras zonas y ciudades del país $(6,21)$. Diversos estudios con información sobre varios países suramericanos entre 2006 y 2008, reportan que, del total de E. faecium cultivados, el 31,0\% presentó resistencia a la vancomicina, siendo Perú el país con el índice más alto (48,0\%), y Colombia con el más bajo (24,0 \%) (22). Entre 2005 y 2008, el programa SENTRY en Brasil reportó 65,7\% de resistencia de $E$. faecium a la vancomicina (23). Este comportamiento puede deberse a la diseminación creciente de clones epidémicos con resistencia a este antibiótico.

Con relación a las bacterias Gram negativas, uno de los hallazgos más importantes en este estudio fue la evolución observada en la resistencia a ciertos antibióticos. Se observó un incremento significativo de la resistencia a la ceftazidima en E. coli, reportado también por Villalobos, et al., entre 2007 y 2009 (6). Asimismo, la tendencia a la disminución de la resistencia a este antibiótico en K. pneumoniae y E. cloacae encontrada en el presente estudio, fue similar a la reportada por el Grupo de Estudio de la Resistencia Nosocomial (sic.) en Colombia en 14 hospitales de tercer nivel 
de siete ciudades del país entre 2006 y 2008, estudio en el que estos dos microorganismos presentaron una disminución estadísticamente significativa de la resistencia a cefalosporinas de tercera generación (24).

El incremento observado en la resistencia de $E$. coli a las cefalosporinas de tercera generación, resulta paradójico frente al descenso en la resistencia que presentó K. pneumoniae a este tipo de antibióticos, teniendo en cuenta que los mismos factores que presionan la aparición y permanencia de este tipo de resistencia operan para ambas especies bacterianas.

En nuestra región la resistencia a las cefalosporinas de tercera generación en E. coli y K. pneumoniae, puede explicarse principalmente por la presencia de betalactamasas de espectro extendido (BLEE) (no se presentan los datos ). En 1997 ya se reportaban cepas de E. coli y K. pneumoniae productoras de BLEE en el 5,7 y el 40,0 \% de los aislamientos, respectivamente, en tres hospitales de Medellín (25). En un estudio más reciente llevado a cabo en ocho hospitales de Bogotá, Cali y Medellín por el Grupo de Estudio de Resistencia Nosocomial (sic.) en Colombia en el 2002, se encontró que 11,8\% de las cepas de E. coli recuperadas de pacientes hospitalizados en las unidades de cuidados intensivos y $8,4 \%$ de las recuperadas en pacientes en salas generales producían BLEE, en tanto que las cifras para K. pneumoniae fueron de 32,6 y $29,8 \%$, respectivamente (26).

La situación en los países vecinos es similar (27). En Brasil la proporción de producción de BLEE en $E$. coli fluctúa entre 10,0 y $18,0 \%$, y en K. pneumoniae, entre 40,0 y $50,0 \%$ (28). Sin embargo, a diferencia de lo que sucede en los países latinoamericanos, los porcentajes de producción de BLEE son menores en los países de la región Asia-Pacífico (con excepción de China), de Europa y de Estados Unidos, con promedios generales de producción de BLEE en K. pneumoniae de 22,4, 13,3 y 7,5 \% en cada región, respectivamente (29).

Si bien es cierto que la resistencia de $E$. coli a los carbapenémicos permaneció constante en estos seis años, en $K$. pneumoniae, S. marcescens y E. cloacae se observó un incremento de la resistencia a partir de 2007. Este comportamiento no es exclusivo de nuestra región. En una revisión sistemática reciente de la resistencia en enterobacterias en Colombia, González, et al., (30) reportaron una tendencia al aumento en la resistencia a los carbapenémicos, en especial en K. pneumoniae y E. cloacae, fenómeno observado en varios países a nivel mundial $(31,32)$.

El primer reporte en nuestra región de cepas de $K$. pneumoniae con resistencia a carbapenémicos mediada por la producción de enzimas de tipo KPC, se presentó en el 2005 en dos hospitales que hacen parte de nuestro grupo de estudio (33). Posteriormente, en el año 2008, se presentó un brote en uno de estos hospitales originado en una cepa de K. pneumoniae del tipo KPC-3 portada por un paciente nacido y residente en Israel, que fue el segundo país del mundo, después de Estados Unidos, en donde hizo su aparición este tipo de bacterias (7).

Los datos de resistencia a carbapenémicos de otras especies de enterobacterias diferentes de $K$. pneumoniae, como S. marcescens y E. cloacae, encontrados en este estudio, sugieren que en nuestra región podría estarse presentando la transmisión y la diseminación entre diferentes especies bacterianas de elementos genéticos móviles que portan los genes de resistencia, fenómeno que ha sido reportado en diversos géneros y especies de la familia Enterobacteriaceae (34-38).

De igual manera, en el hospital en el cual se presentó el brote mencionado, se reportó por primera vez un aislamiento de $P$. aeruginosa resistente a los carbapenémicos y productor de una betalactamasa de tipo carbapenemasa (9). Aunque nuestros datos muestran una tendencia a la disminución de la resistencia a los carbapenémicos en $P$. aeruginosa y $A$. baumannii en este periodo, la multirresistencia es común en estas dos especies bacterianas, especialmente en las unidades de cuidados intensivos, como lo reporta el Grupo para el Estudio de la Resistencia Nosocomial (sic.) en Colombia en un estudio en 23 instituciones hospitalarias del país (39). Dada la capacidad de diseminación de este tipo de aislamientos en el entorno hospitalario, la búsqueda activa de pacientes colonizados, y las medidas de aislamiento y control son fundamentales para su contención.

El cambio reciente en la recomendación de los puntos de corte de la ceftazidima y los carbapenémicos para la interpretación de la sensibilidad en enterobacterias, no implicó un cambio en la tendencia de la resistencia observada con los criterios de interpretación de la guía del CLSI del 2009, con excepción de lo observado en $E$. cloacae. El análisis de este microorganismo con base en los criterios del CLSI para el 2009, mostró 
una tendencia a la disminución de la resistencia a la ceftazidima, pero la adopción de los criterios vigentes significó un incremento en la proporción de aislamientos resistentes a este antibiótico a partir del año 2010. En este sentido, es crucial el análisis de la información que se obtenga en el año en curso para determinar el comportamiento real de la resistencia, lo que también se aplica para la resistencia a imipenem y meropenem en $P$. aeruginosa, microorganismo en el que el cambio en los puntos de corte se implementó solo partir del 2012.

Las limitaciones de este estudio son las que refiere la guía del CLSI M39-A4 para este tipo de estudios (11). Una de ellas es que los datos de sensibilidad utilizados se generan a partir de aislamientos de muestras de pacientes procesadas por los laboratorios y, por lo tanto, están sujetos a las prácticas de toma de muestra de las instituciones participantes. Asimismo, aunque se estima que la mayoría de los aislamientos con datos de sensibilidad provienen de pacientes con infecciones verdaderas, puede existir un porcentaje de ellos que reflejen colonización o contaminación. Como no era posible determinar esto a partir de la base de datos suministrada por cada institución, se incluyeron todos los aislamientos en los análisis. Los análisis en este estudio se hicieron considerando el primer aislamiento de cada paciente, lo que, si bien evita el sesgo que pueden introducir múltiples aislamientos de un mismo caso, omite aislamientos posteriores con perfiles de resistencia diferentes 0 emergentes que pueden ser de interés clínico y epidemiológico.

Las tendencias observadas en el presente estudio no están asociadas a datos de consumo de antibióticos, uno de los factores determinantes en el comportamiento de la resistencia. Esta es una de las fortalezas del sistema nacional de vigilancia que se está implementando a nivel nacional.

Dada la magnitud de la resistencia a los antibióticos, se hace indispensable fortalecer las medidas de prevención y control de infecciones a nivel hospitalario, mejorar la capacidad de los laboratorios para la detección oportuna de microorganismos multirresistentes, así como implementar programas para el uso adecuado de los antimicrobianos. La vigilancia de la resistencia a antimicrobianos es una herramienta que permite entender mejor cómo contribuyen las dinámicas de generación de resistencia en poblaciones microbianas a este fenómeno y el papel que estas juegan en las infecciones asociadas a la atención en salud. Un conocimiento más profundo del problema de la resistencia generará las bases para su contención.

\section{Agradecimientos}

A los integrantes del Grupo GERMEN que participaron activamente en el sistema de vigilancia de la resistencia entre el 2007 y el 2012: Clínica El Rosario, sede Centro y sede Tesoro - Laboratorio Médico de Referencia (Carlos G. Robledo, Jaime Robledo, Luz Beatriz Arroyave, Luz Teresita Giraldo, Natalia A. Maldonado); Hospital Pablo Tobón Uribe (María Isabel Múnera, Ana María Bedoya, Mónica Cuartas, Olga Molina, Ana Restrepo, Gloria Marín); Clínica Cardio VID (Liliana Franco, Gustavo Roncancio, Juan Carlos González, Liliana Romero, Martha Gallo); Clínica CES (Marcela Gaviria, Ana María Restrepo); Clínica del Prado (María Teresa Correa); Clínica Las Américas (Esteban Echavarría, Luz Teresita Correa, Isabel Cristina Valencia, Gloria Durango); Clínica Las Vegas - Dinámica IPS (Victoria Yepes, Ana María Ramírez); Clínica Medellín Laboratorio Clínico Gonzalo Aristizábal (Marcela Gaviria, Gladys Stella Pineda); Clínica SOMA (Alberto Correa, Natalia Llano); Clínica Saludcoop Medellín (Isabel Cristina Ríos, Julio Biojó); Clínica Universitaria Bolivariana - Dinámica IPS (Carlos Alberto Arbeláez, Sandra Marcela Osorno, Carolina Delgado); Fundación Instituto Neurológico de Colombia (Lina María Ochoa, Alba Gallego); IPS Universitaria - Clínica León XIII (Patricia Sierra, Beatriz Estrada); E.S.E. Hospital General de Medellín (Paola Rojas, Walter Zea); Clínica Sagrado Corazón (Sergio Andrés Posada); Clínica Saludcoop Juan Luis Londoño De la Cuesta (Mónica Restrepo, Juliana García); E.S.E. Hospital La María, Clínica Antioquia (Rubén Darío Trejos); E.S.E. Hospital Manuel Uribe Ángel (Gloria Tapias, Adriana García, Marcela Villegas, Carlos Cardona, Yeni Díaz); Clínica SOMER (Fabio Restrepo, Socorro Arango); Fundación Clínica del Norte (Luis Fernando Chaín, Mónica Ossa, Mónica Figueroa); METROSALUD (Consuelo Giraldo, Patricia David); Laboratorio Clínico Prolab S.A.S. (Natalia Loaiza, Juan Carlos Gómez, Ana Cristina Estrada, Johana Romero Palacio); y Laboratorio Clínico VID (Santiago Estrada Mesa, Claudia Vanegas).

\section{Conflicto de intereses}

Los autores del presente estudio declaran no tener conflictos de intereses. 


\section{Financiación}

El Grupo GERMEN ha recibido apoyo de AstraZeneca Colombia S.A., bioMérieux Colombia S.A.S., PFIZER Colombia y Becton Dickinson.

\section{Referencias}

1. World Health Organization. Fifty-first World Assembly, Emerging and other communicable diseases: Antimicrobial resistance - 1998. Fecha de consulta: 8 de mayo de 2013. Disponible en: http://apps.who.int/medicinedocs/documents/ s16334e/s16334e.pdf.

2. European Centre for Disease Prevention and Control (ECDC). Annual Epidemiological Report on Communicable Diseases in Europe - 2010. Fecha de consulta: 8 de mayo de 2013. Disponible en: http://www.ecdc.europa. eu/en/publications/publications/1011_sur_annual_ epidemiological_report_on_communicable_diseases_in_ europe.pdf.

3. Organización Mundial de la Salud. Estrategia Mundial de la OMS para Contener la Resistencia a los Antimicrobianos - 2001. Fecha de consulta: 4 de mayo de 2013. Disponible en: http://www.who.int/drugresistance/SpGlobal2.pdf?ua=1

4. Ministerio de la Protección Social - República de Colombia. Informe científico de la Red. Estado del arte de la resistencia bacteriana y de la vigilancia epidemiológica de las infecciones asociadas al cuidado de la salud en Colombia. Fecha de consulta: 20 de abril de 2013. Disponible en: http:// www.ins.gov.co/temas-de-interes/IAAS/4.\%20Estado\%20 del\%20arte\%20de\%20resistencia\%20bacteriana.pdf.

5. Instituto Nacional de Salud. ¿Qué es la Red PREVINS? Fecha de consulta: 5 de abril de 2013. Disponible en: www. ins.gov.co/iaas/Paginas/que-es-la-RED-PREVINS.aspx.

6. Villalobos-Rodríguez AP, Díaz-Ortega MH, BarreroGarzón LI, Rivera-Vargas SM, Henríquez-Iguarán DE, Villegas-Botero MV, et al. Tendencias de los fenotipos de resistencia bacteriana en hospitales públicos y privados de alta complejidad de Colombia. Rev Panam Salud Pública. 2011:30:627-33. http://dx.doi.org/10.1590/S102049892011001200022

7. López JA, Correa A, Navon-Venezia S, Correa AL, Torres JA, Briceño DF, et al. Intercontinental spread from Israel to Colombia of a KPC-3-producing Klebsiella pneumoniae strain. Clin Microbiol Infect. 2011;17:52-6. http://dx.doi.org/10. 1111/j.1469-0691.2010.03209.x

8. Cuzon G, Naas T, Villegas MV, Correa A, Quinn JP, Nordmann P. Wide dissemination of Pseudomonas aeruginosa producing beta-lactamase blaKPC-2 gene in Colombia. Antimicrob Agents Chemother. 2011;55:5350-3. http://dx.doi/10.1128/AAC.00297-11

9. Villegas MV, Lolans K, Correa A, Kattan JN, López JA, Quinn JP. First identification of Pseudomonas aeruginosa isolates producing a KPC-type carbapenemhydrolyzing beta-lactamase. Antimicrob Agents Chemother. 2007;51:1553-5. http://dx.doi:10.1128/AAC.01405-06

10. Escobar JA, Olarte NM, Castro-Cardozo B, Valderrama IA, Garzón MI, Martínez L, et al. Outbreak of NDM-1producing Klebsiella pneumoniae in a neonatal unit in Colombia. Antimicrob Agents Chemother. 2013;57:1957-60. http://dx.doi.org/10.1128/AAC.01447-12
11. Clinical and Laboratory Standards Institute. Analysis and presentation of cumulative antimicrobial susceptibility test data; approved guideline. Fourth edition. CLSI document M39-A4. Wayne, PA: CLSI; 2014.

12. Boucher HW, Talbot GH, Bradley JS, Edwards JE, Gilbert D, Rice LB, et al. Bad bugs, no drugs: No ESKAPE! An update from the Infectious Diseases Society of America. Clin Infect Dis. 2009;48:1-12. http://dx.doi.org/10.1086/595011

13. Clinical and Laboratory Standards Institute. Performance standards for antimicrobial susceptibility testing; Nineteenth Informational Supplement. CLSI document M100-S19. Wayne, PA: CLSI; 2009.

14. Clinical and Laboratory Standards Institute. Performance standards for antimicrobial susceptibility testing; TwentyThird Informational Supplement. CLSI document M100S23. Wayne, PA: CLSI; 2013.

15. Grupo para el Control de la Resistencia Bacteriana de Bogotá - GREBO. Resultados del Proyecto: "Impacto clínico y económico de la resistencia bacteriana en hospitales del Distrito". Fecha de consulta: 8 de marzo de 2014. Disponible en: http://grebo.org/grebo_site/jgrebo/ documentos/Boletin\%20Informativo\%20No\%20S1\%20 2010.pdf.

16. Garza-González E, Dowzicky MJ. Changes in Staphylococcus aureus susceptibility across Latin America between 2004 and 2010. Braz J Infect Dis. 2013;17:13-9. http://dx. doi.org/10.1016/j.bjid.2012.08.017

17. Lagacé-Wiens PR, Adam HJ, Low DE, Blondeau JM, Baxter MR, Denisuik AJ, et al. Trends in antibiotic resistance over time among pathogens from Canadian hospitals: Results of the CANWARD study 2007-11. J Antimicrob Chemother. 2013;68:23-9. http://dx.doi.org/10. 1093/jac/dkt023

18. Livermore DM. Fourteen years in resistance. Int J Antimicrob Agents. 2012;39:283-94.http://dx.doi.org/10.1016/j.ijantimicag. 2011.12.012

19. Stefani S, Chung DR, Lindsay JA, Friedrich AW, Kearns AM, Westh $\mathbf{H}$, et al. Meticillin-resistant Staphylococcus aureus (MRSA): Global epidemiology and harmonization of typing methods. Int J Antimicrob Agents. 2012;39:273-82. http://dx.doi.org/10.1016/j.jiantimicag.2011.09.030

20. Dhand A, Sakoulas G. Reduced vancomycin susceptibility among clinical Staphylococcus aureus isolates ('the MIC Creep'): Implications for therapy. F1000 Med Rep. 2012;4:4. http://dx.doi.org/10.3410/M4-4

21. Espinosa CJ, Cortés JA, Castillo JA, Leal AL. Revisión sistemática de la resistencia antimicrobiana en cocos Gram positivos intrahospitalarios en Colombia. Biomédica. 2011; 31:27-34. http://dx.doi.org/10.7705/biomedica.v31i1.333

22. Panesso D, Reyes J, Rincón S, Díaz L, Galloway-Peña $\mathbf{J}$, Zurita $\mathbf{J}$, et al. Molecular epidemiology of vancomycinresistant Enterococcus faecium: A prospective, multicenter study in South American hospitals. J Clin Microbiol. 2010;48:1562-9. http://dx.doi.org/10.1128/JCM.02526-09

23. Gales AC, Sader HS, Ribeiro J, Zoccoli C, Barth A, Pignatari AC. Antimicrobial susceptibility of gram-positive bacteria isolated in Brazilian hospitals participating in the SENTRYProgram (2005-2008). BrazJ InfectDis. 2009;13:90-8. http://dx.doi.org/10.1590/S1413-86702009000200004 
24. Briceño DF, Correa A, Valencia C, Torres JA, Pacheco R, Montealegre MC, et al. Grupo de Resistencia Bacteriana Nosocomial de Colombia. Actualización de la resistencia a antimicrobianos de bacilos Gram negativos aislados en hospitales de nivel III de Colombia: años 2006, 2007 y 2008. Biomédica 2010;30:371-81. http://dx.doi.org/10.7705/ biomedica.v30i3.271

25. Robledo J, López J, Sierra P, Robledo C, Pfaller M, Jones RN. El Programa de Vigilancia Antimicrobiana SENTRY en Colombia, hallazgos iniciales en tres hospitales de Medellín. Infectio. 1999;3:100-7.

26. Villegas MV, Correa A, Pérez F, Miranda MC, Zuluaga T, Quinn JP, et al. Prevalence and characterization of extendedspectrum beta-lactamases in Klebsiella pneumoniae and Escherichia coli isolates from Colombian hospitals. Diagn Microbiol Infect Dis. 2004;49:217-22.

27. Villegas MV, Blanco MG, Sifuentes-Osornio J, Rossi F. Increasing prevalence of extended-spectrum-betalactamase among Gram-negative bacilli in Latin America - 2008 update from the Study for Monitoring Antimicrobial Resistance Trends (SMART). Braz J Infect Dis. 2011;15:34-9. http://dx. doi.org/10.1590/S1413-86702011000100007

28. Rossi F. The challenges of antimicrobial resistance in Brazil. Clin Infect Dis. 2011;52:1138-43. http://dx.doi.org/10.1093/ $\mathrm{cid} / \mathrm{cir} 120$

29. Dhillon RH, Clark J. ESBLs: A clear and present danger? Crit Care Res Pract. 2012;2012:625170. http://dx.doi.org/10. $1155 / 2012 / 625170$

30. González L, Cortés JA. Revisión sistemática de la resistencia antimicrobiana en enterobacterias en aislamientos intrahospitalarios en Colombia. Biomédica. 2014;34:18097. http://dx.doi.org/10.7705/biomedica.v34i2.1550

31. Navon-Venezia S, Leavitt A, Schwaber MJ, Rasheed JK, Srinivasan A, Patel JB, et al. First report on a hyperepidemic clone of KPC-3-producing Klebsiella pneumoniae in Israel genetically related to a strain causing outbreaks in the United States. Antimicrob Agents Chemother. 2009;53:81820. http://dx.doi.org/10.1128/AAC.00987-08

32. Nordmann P, Cuzon G, Naas T. The real threat of Klebsiella pneumoniae carbapenemase-producing bacteria. Lancet
Infect Dis. 2009;9:228-36. http://dx.doi.org/10.1016/S14733099(09)70054-4

33. Villegas MV, Lolans K, Correa A, Suárez CJ, López JA, Vallejo M, et al. First detection of the plasmid-mediated class A carbapenemase KPC-2 in clinical isolates of Klebsiella pneumoniae from South America. Antimicrob Agents Chemother. 2006;50:2880-2. http://dx.doi.org/10.1128/AAC. 00186-06

34. Protonotariou E, Tsalidou M, Vitti D, Kalogeridis A, Sofianou D. First identification of VIM-1-producing Citrobacter freundii in Greece. Int J Antimicrob Agents. 2008;32:460461. http://dx.doi.org/10.1016/j.ijantimicag.2008.05.008

35. Cai JC, Zhou HW, Zhang R, Chen GX. Emergence of Serratia marcescens, Klebsiella pneumoniae, and Escherichia coli isolates possessing the plasmid-mediated carbapenem-hydrolyzing $\beta$-lactamase KPC-2 in intensive care units of a Chinese hospital. Antimicrob Agents Chemother 2008;52:2014-8. http://dx.doi.org/10.1128/AAC. 01539-07

36. Rasheed JK, Biddle JW, Anderson KF, Washer L, Chenoweth C, Perrin J, et al. Detection of the Klebsiella pneumoniae carbapenemase type 2 carbapenem-hydrolyzing enzyme in clinical isolates of Citrobacter freundii and $K$. oxytoca carrying a common plasmid. J Clin Microbiol 2008; 46:2066-9. http://dx.doi.org/10.1128/JCM.02038-07

37. Sheng ZK, Li JJ, Sheng GP, Sheng JF, Li LJ. Emergence of Klebsiella pneumoniae carbapenemase-producing Proteus mirabilis in Hangzhou, China. Chin Med J (Engl). 2010;123:2568-70.

38. Richter SN, Frasson I, Bergo C, Parisi S, Cavallaro A, Palù G. Transfer of KPC carbapenemase from Klebsiella pneumoniae to Escherichia coli in a patient: First case in Europe. J Clin Microbiol. 2011;49:2040-2. http://dx.doi.org/10. 1128/JCM.00133-11

39. Hernández-Gómez C, Blanco VM, Motoa G, Correa A, Maya JJ, de la Cadena E, et al. Evolución de la resistencia antimicrobiana en bacilos Gram negativos en unidades de cuidados intensivos en Colombia. Biomédica. 2014;34(Supl.1):91-100. http://dx.doi.org/10.7705/biomedica. v34i0.1667 